\title{
Malaria and the heart
}

\author{
Smitha Bhat, Jayaprakash Alva, Krithika Muralidhara, Sayid Fahad
}

Department of Medicine, Father Muller Medical College, Mangalore, Karnataka, India

Correspondence to Dr Smitha Bhat, doctorsmitha@yahoo.co.in

\section{Summary}

A 40-year-old healthy manual labourer from a malaria endemic area with no known risk factors for atherosclerotic coronary vascular disease was admitted to our hospital with a history of fever with chills and rigours. Physical examination revealed tachypnoea and icterus. Peripheral smear showed trophozoites of Plasmodium vivax and thrombocytopaenia. The patient was administered artesunate. Six hours after admission, he complained of severe substernal chest pain. A 12-lead ECG revealed ST elevations in leads I, II and aVL. Troponin T and creatine kinase MB were elevated and the random blood sugar was $49 \mathrm{mg} \%$. Echocardiogram revealed left ventricle lateral wall hypokinesia. Hypoglycaemia was corrected. A provisional diagnosis of acute coronary syndrome as a complication of malaria or its treatment was made. He was treated with low molecular weight heparin and nitrates. The patient improved symptomatically. A repeat ECG was normal.

\section{BACKGROUND}

The absence of pre-existing risk factors for coronary artery disease, the temporal association with malaria and the complete reversion of the ECG to normal make this case interesting. We would also like to highlight the therapeutic dilemma that was faced. In a patient with malaria and thrombocytopaenia who develops acute coronary syndrome (ACS), whether the patient should be treated with antiplatelet agents was a question which we had to answer.

\section{CASE PRESENTATION}

The patient $\mathrm{Mr} \mathrm{H}$ is a 40 -year-old manual labourer who presented with a 3-day history of fever associated with chills, rigours and headache. There was no history of diabetes, hypertension, dyslipidemia or smoking. There was no family history of dyslipidemia or coronary artery disease. The blood pressure on admission was $130 / 80 \mathrm{~mm} \mathrm{Hg}$ and temperature was $39.6^{\circ} \mathrm{C}$. There was no neck stiffness and the systemic examination was essentially normal. Investigations revealed Plasmodium vivax malaria with thrombocytopaenia. The random blood sugar (RBS) was normal. The patient was started on treatment with artesunate $200 \mathrm{mg} /$ day and paracetamol. On the same day, $6 \mathrm{~h}$ after admission, he complained of severe retrosternal compressive chest pain associated with sweating. The blood pressure was $90 / 60 \mathrm{~mm} \mathrm{Hg}$, heart rate $80 / \mathrm{min}$ and jugular venous pressure was normal. An ECG recorded at that time showed a significant ST elevation in leads I, II and aVL. Troponin $\mathrm{T}$ and creatine kinase $(\mathrm{CK}) \mathrm{MB}$ were elevated (figures 1 and 2). The chest pain lasted for around $15 \mathrm{~min}$ and was relieved with sublingual nitrates. Glucometer random blood sugar (GRBS) at that time was $49 \mathrm{mg} \%$.

\section{INVESTIGATIONS}

-White blood cell count-4000/ $\mathrm{mm}^{3}$. Platelet count$77000 / \mathrm{mm}^{3}$

- Arterial blood gas- $\mathrm{pH}$ 7.24, $\mathrm{pCO}_{2} 43, \mathrm{pO}_{2} 89$ and $\mathrm{HCO}_{3} 18.4$

- Prothrombin time, international normalized rationormal

- Smear for malaria parasite-positive trophozoites and gametocytes of $P$ vivax, moderate thrombocytopaenia (figures 5 and 6 ).

- CKMB $38.2(<24)$

- Trop t $-520-<50 \mathrm{ng} / \mathrm{l}$

- Echo-ischaemic heart disease-hypokinesia lateral wall left ventricle

- Renal function tests-normal

- Fasting lipid profile and fasting blood sugar-normal.

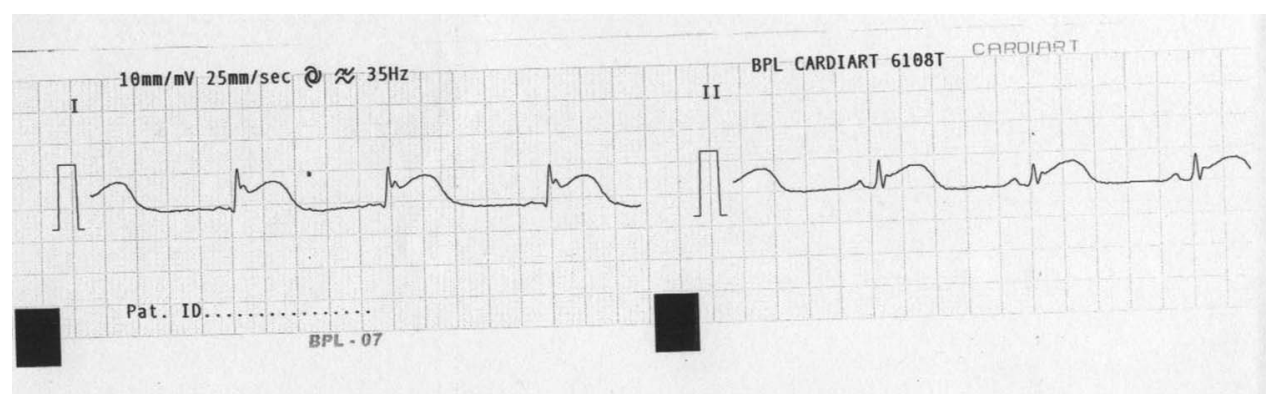

Figure 1 ECG showing ST elevation in leads I and II. 


\section{BMJ Case Reports}

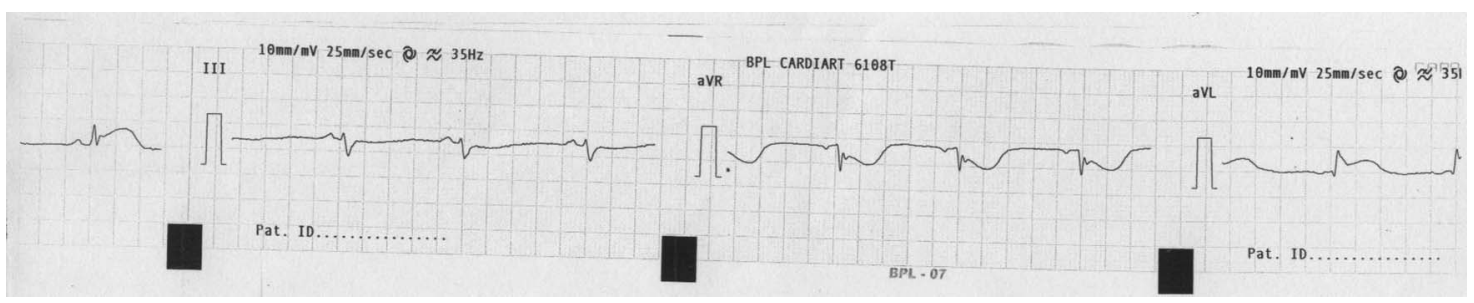

Figure 2 ECG showing ST elevation in lead aVL.

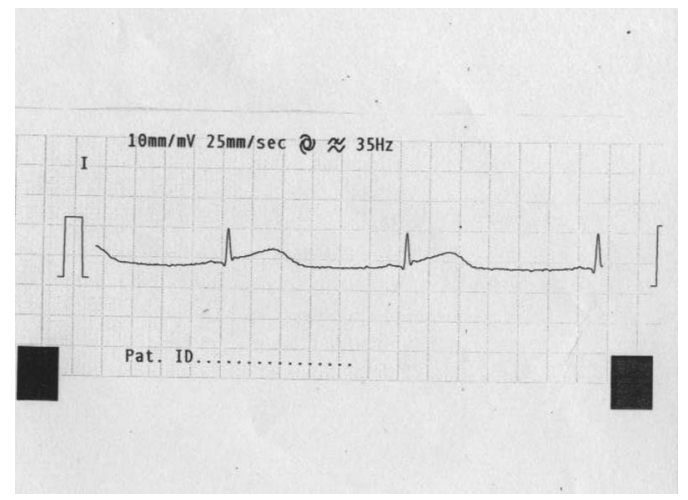

Figure 3 ECG showing reversion of ST elevation in lead I.

\section{TREATMENT}

The patient was initially started on treatment for vivax malaria as per WHO guidelines. When he was diagnosed to have ACS he was shifted to the coronary care unit. He was treated with nitrates, metoprolol and low molecular weight heparin (enoxaparin). The patient refused thrombolysis and coronary angiography in view of severe financial constraints. Antiplatelet agents were withheld in view of the existing thrombocytopaenia. The chest pain was relieved after 15 min after administration of sublingual nitrates, and another ECG performed an hour later was normal (figures 3 and 4). The patient was discharged after 5 days on primaquine and ecosprin.

\section{OUTCOME AND FOLLOW-UP}

The patient was asymptomatic at discharge. He visited our outpatient department two weeks later for a reviewthere were no symptoms of exertional chest pain and/or breathlessness.

\section{DISCUSSION}

Malaria is a disease caused by the protozoan Plasmodium falciparum, vivax and ovale and transmitted by the infected anopheles mosquito. The estimated annual incidence of malaria varies between 10 and 500 million cases annually. It causes approximately a million deaths annually. Malaria is a disease of the tropics - with the annual incidence being the highest in sub-Saharan Africa and South-East Asia. ${ }^{1}$

Malaria causes symptoms by invasion of and multiplication in red blood cells (RBCs). The plasmodium consumes the haemoglobin and other intracellular proteins in RBCs. Additionally, it affects the structure of the RBCs changing its shape and making it less deformable. $P$ falciparum specifically causes cytoadherence where the infected RBCs stick to the walls of capillaries. Cytoadherence causes the parasitised RBCs to become sequestered in capillaries of the brain and heart. This results in their blockage. However, sequestration does not occur in the case of vivax malaria. ${ }^{2}$

Falciparum malaria can be complicated owing to acute renal insufficiency, cerebral malaria, acidosis and acute respiratory distress syndrome (ARDS). Traditionally, vivax malaria is considered to be less dangerous and has been termed as benign tertian malaria. However, the epidemiology and clinical course of vivax malaria appears to be changing with cases of vivax malaria being complicated with ARDS, acute kidney injury, anaemia and cerebral malaria. ${ }^{3}$ Considering the high incidence of malaria in sub-Saharan Africa, India and South-East Asia, very few cardiac complications have been reported. ${ }^{4} 5$ Malaria may be a risk factor for acute myocardial infarction (MI). A retrospective observational study in Mangalore in 2010 found a significantly higher rate of MI in patients hospitalised for malaria than in those admitted for other causes. However, the majority of cases with MI suffered from falciparum rather than vivax malaria. ${ }^{6}$ MI has also been reported as a complication in experimental malaria. ${ }^{7}$

Another cardiovascular complication that has been reported with malaria is myocarditis. However, this has been reported with falciparum malaria rather than vivax malaria. ${ }^{8}$

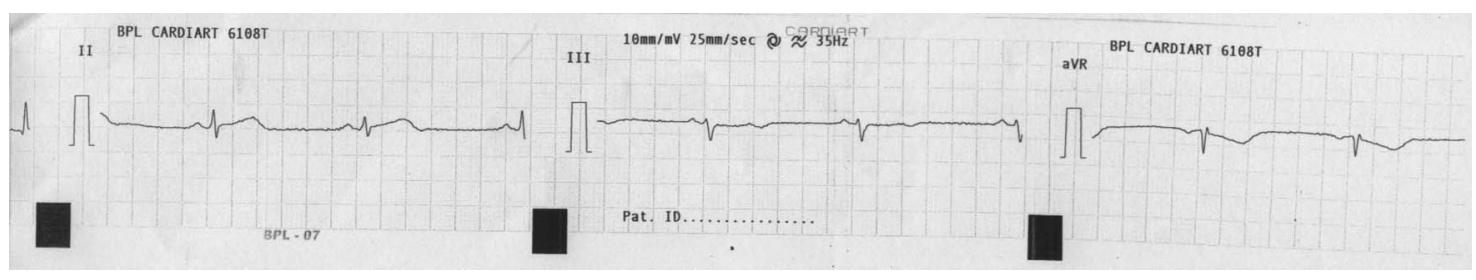

Figure 4 ECG showing reversion of ST elevation in Lead II. 


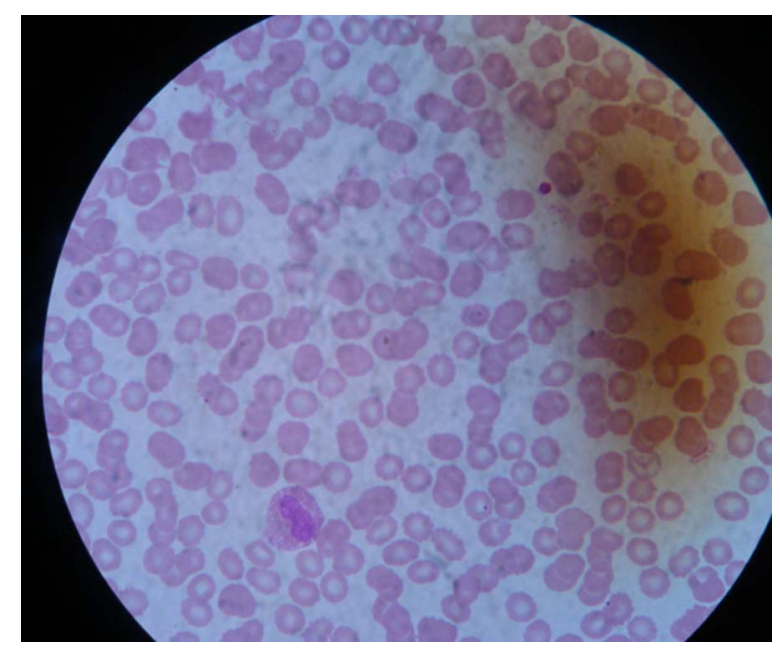

Figure 5 Peripheral smear showing Plasmodium vivax and thrombocytopaenia.

We present this young adult male with no risk factors for a coronary artery disease who developed ACS during a hospital stay for the treatment of malaria. The absence of pre-existing risk factors for a coronary artery disease, the temporal association of the chest pain with malaria and the complete reversion of the ECG to normal make this case interesting. That malaria (particularly falciparum malaria) can cause cardiac ischaemia by sequestration and coronary vascular occlusion is biologically plausible, and the first possibility to be considered is whether malaria-induced capillary occlusion was responsible for the ACS in this patient. However, cardiac complica-

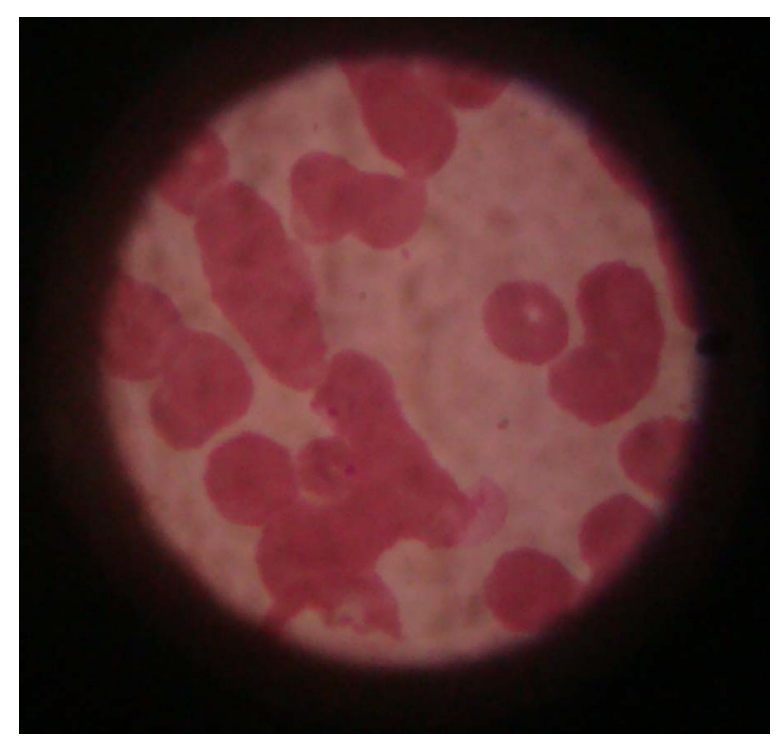

Figure 6 Peripheral smear showing Plasmodium vivax and thrombocytopaenia. tions are uncommon in a patient suffering from vivax malaria. The second possibility to be considered is whether malaria-induced hypoglycaemia precipitated the ACS in our patient. Malaria can cause hypoglycaemia as a severe infection hinders gluconeogenesis, and there is an increased consumption of glucose by the parasite. ${ }^{2}$

Hypoglycaemia may cause increased sympathetic activity and increased cardiac work and thus may precipitate coronary ischaemia in a patient with pre-existing ischaemic heart disease. However, it is less likely in our patient showing no risk factors for atherosclerosis.

The temporal association with the treatment by artemether raises the possibility that the ACS is related to the drug. The product information on this drug advises its use with caution if OT prolongation occurs, but ACS has not been documented as an adverse effect of artemether.

The last possibility is that the patient had Printzmetal or vasospastic angina and the infection with malaria was a mere coincidence.

\section{Learning points}

- Hypoglycaemia must be considered when any patient with malaria exhibits a sudden deterioration.

- The term benign tertian malaria is a misnomer and vivax malaria can also have a complicated course.

- That malaria can be complicated with acute respiratory distress syndrome and renal insufficiency is well known. However, the possibility that malaria may be associated with the cardiovascular system must be considered.

Competing interests None.

Patient consent Obtained.

\section{REFERENCES}

1. White NJ, Breman JG. Malaria. In: Fauci, Kasper, Hauser, Jameson, Loscalzo Longo. Harrison's principles of internal medicine. New York, USA: McGraw Hill, 2012.

2. Kochar DK. Severe Plasmodium vivax malaria: a report on serial cases from Bikaner in northwestern India. Am J Trop Med Hyg 2009;80:194-8.

3. Franzen D, Curtius JM, Heitz W, et al. Cardiac involvement during and after malaria. Clin Invest 1992;70:670-3.

4. Bethell DB, Phuong PT, Phuong CX, et al. Electrocardiographic monitoring in severe falciparum malaria. Trans $R$ Soc Trop Med Hyg 1996;90:266-9.

5. Nieman AE, de Mast Q, Roestenberg M, et al. Cardiac complication after experimental human malaria infection: a case report. Malar J 2009;8:277.

6. Mohsen AH, Green ST, West JN, et al. Myocarditis associated with Plasmodium falciparum malaria: a case report and a review of the literature. J Travel Med 2001;8:219-20.

7. Jain K, Chakrapani M. Acute myocardial infarction in a hospital cohort of malaria. J Glob Infect Dis 2010;2:72-3.

8. Murray CJL, Lopez AP. (eds) The global burden of disease: a comprehensive assessment of mortality and disability from diseases, injuries and risk factors in 1990 and projected to 2020. Switzerland, Geneva: World Health Organization, 1996. 


\section{BMJ Case Reports}

Copyright 2012 BMJ Publishing Group. All rights reserved. For permission to reuse any of this content visit http://group.bmj.com/group/rights-licensing/permissions.

BMJ Case Report Fellows may re-use this article for personal use and teaching without any further permission.

Please cite this article as follows (you will need to access the article online to obtain the date of publication).

Bhat S, Alva J, Muralidhara K, Fahad S. Malaria and the heart. BMJ Case Reports 2012;10.1136/bcr-2012-007275, Published XXX

Become a Fellow of BMJ Case Reports today and you can:

- Submit as many cases as you like

- Enjoy fast sympathetic peer review and rapid publication of accepted articles

- Access all the published articles

- Re-use any of the published material for personal use and teaching without further permission

For information on Institutional Fellowships contact consortiasales@bmjgroup.com

Visit casereports.bmj.com for more articles like this and to become a Fellow 